\title{
PEMODELAN REGRESI LOGISTIK PADA FAKTOR FISIK DAN KELELAHAN KERJA DENGAN RISIKO KERJA PEKERJA PROYEK PEMBANGUNAN JALAN TOL MEDAN - BINJAI DI PT. HUTAMA KARYA INFRASTRUKTUR
}

\author{
Novrika Silalahi, Natalia Magdalena Simbolon \\ Institut Kesehatan Deli Husada Deli Tua \\ Fakultas Kesehatan Masyarakat \\ e-mail: novrikasilalahi29@gmail.com
}

\begin{abstract}
Infrastructure take hold of an important role as one of the cogs of economic growth and development in every country including Indonesia. The negative impacts arising from the process of infrastructure development / construction are the emergence of work accident rates due to the risk of unsafe work environments and unsafe actions taken by workers. This research is an analytical survey with Cross Sectional Design involving 150 employees of PT. Hutama Karya Infrastruktur as a population and uses the Slovin formula as a sample of 60 people. Data obtained by interview and using questionnaires. Analysis of the data used is univariate, bivariate using the chi-square test and mutivariate using the Multiple Logistic Regression Test with the enter method. Based on the chi square test, the results obtained variables related to work risk are dust in the work environment ( $p$ $<0.017)$, noise $(p=0.025)$, work fatigue $(p=0.005)$. The results showed that the three variables were candidates who entered into the multivariate analysis modeling namely dust in the work environment, noise, and work fatigue. The most related or dominant analysis result is work fatigue variable $(2,268)$. Therefore, researchers suggest that workers always apply SOP on safety to avoid the risk of work accidents.
\end{abstract}

Keywords:logistic regression, work wisk, work accident

\section{Pendahuluan}

Pekerjaan kontruksi merupakan kombinasi dari berbagai macam disiplin ilmu pengetahuan, baik dilihat dari segi teknisnya dan termasuk juga di dalamnya unsur sumber daya manusianya. Dalam pekerjaan konstruksi selalu menyangkut dengan penyelenggaraan pekerjaan konstruksi dan masyarakat penyelenggara pekerjaan konstruksi itu sendiri. Dimana penyelenggaraan pekerjaan konstruksi ini wajib memenuhi ketentuan tentang keteknikan, keselamatan dan kesehatan kesehatan kerja (K3), perlindungan tenaga kerja, serta tata lingkungan setempat untuk menjamin terwujudnya tertib penyelenggaraan pekerjaan konstruksi (Doloksaribu, 2018).

Pengaruh negatif dari proses pembangunan konstruksi yaitu munculnya angka kecelakaan kerja akibat resiko lingkungan kerja yang 
tidak aman dan tindakan tidak aman. Penyebabnya yaitu pekerjaan jasa konstruksi berada pada lingkungan yang hampir selalu berada di tempat terbuka, dan akses yang mudah untuk dimasuki orang yang berbeda, dimana kondisi tersebut tidak mendukung untuk $k 3$, sehingga berpotensi untuk terjadi kecelakaan kerja (Hinze, 1997 dalam Hesti 2006).

Kerugian dan kecelakaan yang dialami perusahaan bervariasi, yang meliputi unsur manusia, mesin (material) dan lingkungan kerja. Di tingkat global, berdasarkan data Organisasi Buruh International (ILO) 2019, setiap tahun sekitar 380.000 pekerja atau 13,7 persen dari 2, 78 juta orang meninggal setiap tahun akibat kecelakaan kerja atau penyakit akibat kerja, salah satu penyebab yaitu karena masih rendahnya kesadaran pengusaha dan karyawan akan pentingnya penerapan Kesehatan dan Keselamatan Kerja (K3).

Berdasarkan laporan tahunan kecelakaan kerja yang diperoleh dari BPJS Ketenagakerjaan, tahun 2011 terjadi kenaikan menjadi 99.491 kasus, dimana hampir $32 \%$ dari kasus kecelakaan tersebut terjadi di sektor konstruksi dan termasuk didalamnnya proyek jalan tol. Pada tahun 2013 terjadi 103.285 kasus kecelakaan kerja dengan ratarata kecelakaan kerja terdapat 283 kasus setiap harinya. Pada tahun 2015 kasus kecelakaan kerja di Indonesia meningkat menjadi 110.285 kasus kecelakaan kerja. Dari angka di atas dapat dikatakan pada sektor konstruksi, kasus kecelakaan kerja termasuk angka yang masih tinggi di beberapa negara (Doloksaribu, 2018).

PT. Hutama Karya Infrastruktur (HKI) merupakan salah satu perusahaan Badan Usaha Milik Negara yang bergerak dibidang jasa konstruksi. Saat ini HKI tengah berfokus pada konstruksi Jalan Tol Trans Sumatera (JTTS). Proyek pembangunan ini adalah proyek pembangunan Jalan Tol Medan Binjai yang berada di Jalan KL. Yos Sudarso. Jumlah Pekerja saat ini sebanyak 150 pekerja yang terbagi menjadi beberapa unit jenis pekerjaan.

Salah satu proyek yang sedang dilaksanakan adalah proyek pembangunan jalan tol Medan-Binjai. Dari data perusahaan, sebagian besar kecelakaan kerja terjadi akibat faktor manusia serta faktor lingkungan kerja. Dari hasil observasi, peneliti menemukan banyak debu bertebaran di lingkungan kerja, dan juga terdapat kebisingan saat melakukan pekerjaan pemancangan dari suara mesin. Hari kerja pekerja di Proyek Waktu para perkerja dalam pembangunan jalan tol Medan Binjai adalah hari Senin - Minggu dengan waktu lembur yang tidak terduga. Hal tersebut mengakibatkan terjadi kelelahan pada pekerja. Berdasarkan uraian diatas maka peneliti tertarik melakukan penelitian tentang apakah ada hubungan faktor fisik (paparan debu, kebisingan) dan kelelahan dengan resiko kecelakaan kerja pada pekerja pembangunan jalan tol Medan - Binjai di PT. Hutama Karya Infrastruktur. 


\section{Metode Penelitian}

Jenis penelitin ini bersifat analitik dengan desain cross sectional, yang bertujuan untuk mengetahui hubungan antara variabel terikat pada penelitian ini. Populasi penelitian adalah seluruh pekerja proyek pembangunan jalan tol Medan - Binjai PT. Hutama Karya Infrastruktur yang berjumlah 150 orang. Sampel penelitian ini ditentukan secara sampling acak sebanyak 60 orang. Data dalam penelitian ini dikumpulkan menggunakan kuesioner dan pencatatan hasil dari pengamatan. Data yang didapatkan kemudian dianalisis dengan analisis univariat, bivariat, dan multivariat. Analisis multivariat yaitu analisis yang menghubungkan beberapa variabel independen dengan satu variabel dependen dalam waktu yang bersamaan. Regresi logistik adalah salah satu analisis multivariat untuk menghubungkan beberapa variabel independen dengan satu variabel dependen dalam waktu yang bersamaan, dimana dalam penelitian ini akan dilakukan pemodelan prediksi. Model prediksi bertujuan untuk memperoleh model dari beberapa variabel independen yang dianggap tepat memprediksi variasi pada variabel dependen.

\section{Hasil dan Pembahasan}

Dari hasil analisis, untuk univariat akan dipaparkan frekuensi dan persentase variabel dependen dan independen yaitu paparan debu, kebisingan, kelelahan kerja dan risiko kecelakaan kerja.
Tabel 1. Hasil Univariat

\begin{tabular}{|c|c|c|c|}
\hline No. & Variabel & $\mathbf{F}$ & $\begin{array}{c}\text { Persentase } \\
(\%)\end{array}$ \\
\hline & Paparan De & & \\
\hline \multirow[t]{4}{*}{1.} & 1. Tinggi & 34 & 56,7 \\
\hline & 2. Rendah & 26 & 43,3 \\
\hline & Total & 60 & 100,0 \\
\hline & Kebisingan & & \\
\hline \multirow[t]{4}{*}{2.} & 1. Tinggi & 39 & 65,0 \\
\hline & 2. Rendah & 21 & 35,0 \\
\hline & Total & 60 & 100,0 \\
\hline & Kelelahan K & & \\
\hline \multirow[t]{4}{*}{3.} & 1. Berat & 44 & 73,3 \\
\hline & 2. Ringan & 16 & 26,7 \\
\hline & Total & 60 & 100,0 \\
\hline & Risiko Kece & aan & Kerja \\
\hline \multirow[t]{3}{*}{4.} & 1. Rendah & 19 & 31,7 \\
\hline & 2. Tinggi & 41 & 68,3 \\
\hline & Total & 60 & 100,0 \\
\hline
\end{tabular}

Dari hasil Tabel 1 menunjukkan bahwa paparan debu yang diperoleh responden saat bekerja sebanyak 34 orang $(56,7 \%)$ mengatakan terpapar debu, dan sebanyak 26 orang $(43,3 \%)$ mengatakan tidak terpapar oleh debu. Kebisingan yang ada di lingkungan kerja yang diterima responden dala kategori tinggi sebanyak 39 orang (65\%), dan kebisingan dengan kategori rendah sebanyak 21 orang (35\%). Kelelahan yang diterima responden di lingkungan kerja dengan tingkat yang berat sebanyak 44 orang $(73,3 \%)$, dan kelelahan dengan tingkat yang ringan sebanyak 16 orang $(26,7 \%)$. Risiko kecelakaan kerja yang ada di lingkungan kerja dengan tingkat yang rendah sebanyak 19 orang $(31,7 \%)$, dan resiko kecelakaan kerja dengan tingkat yang tinggi sebanyak 41 orang $(68,3 \%)$. 


\section{A. Analisis Bivariat}

Analisis bivariat bertujuan untuk mengetahui hubungan variabel bebas (paparan debu, kebisingan, dan kelelahan) terhadap variabel terikat (risiko kecelakaan kerja). Dengan menggunakan uji Chi-Square dengan nilai a (Alpha) adalah 0,05 $(5 \%)$.

Tabel 2. Hubungan Paparan Debu dengan Risiko Kecelakaan Kerja

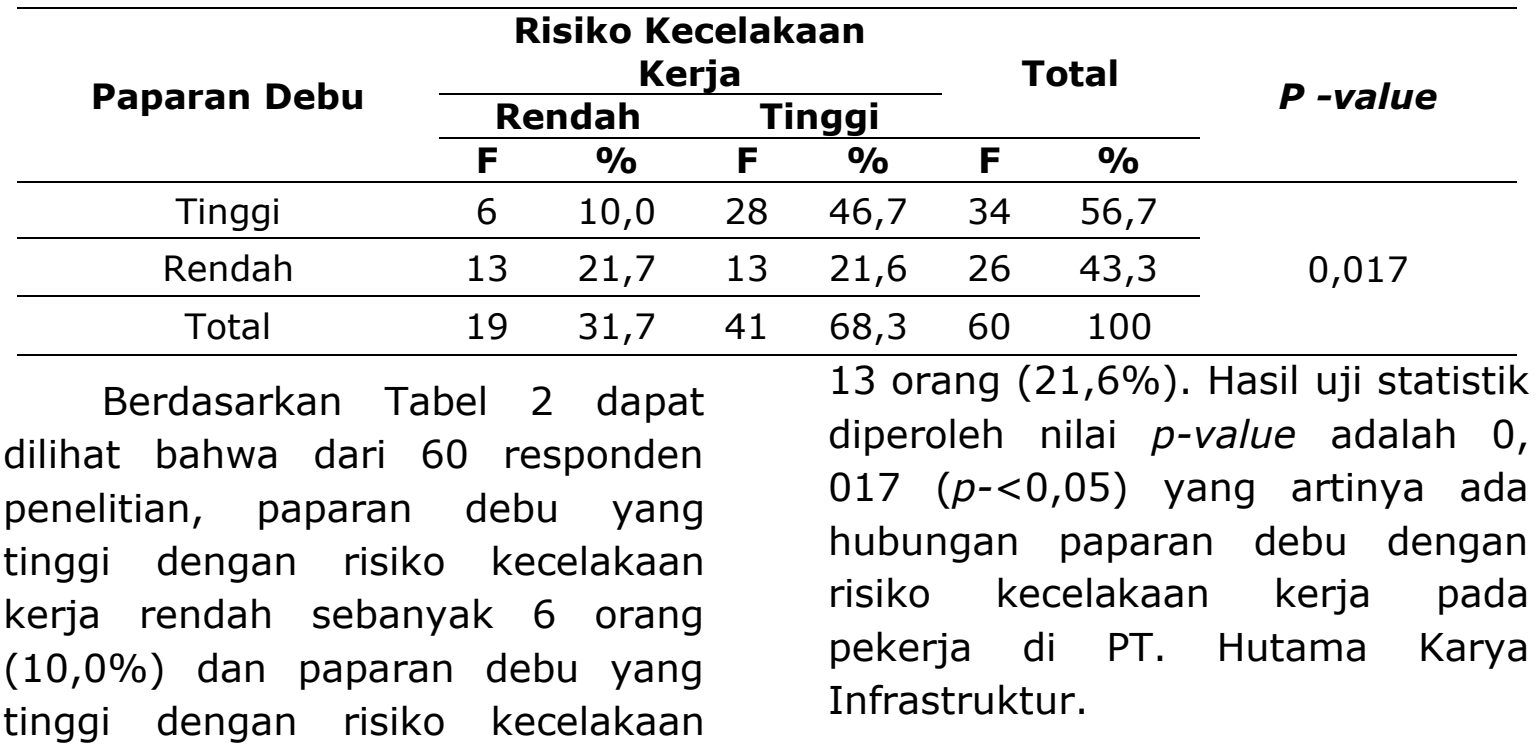
kerja tinggi sebanyak 28 orang $(46,7 \%)$. Sedangkan paparan debu yang rendah dengan risiko kecelakaan kerja rendah sebanyak 13 orang $(21,7 \%)$ dan paparan debu yang rendah dengan risiko kecelakaan kerja tinggi sebanyak

Tabel 3. Hubungan Kebisingan dengan Risiko Kecelakaan Kerja

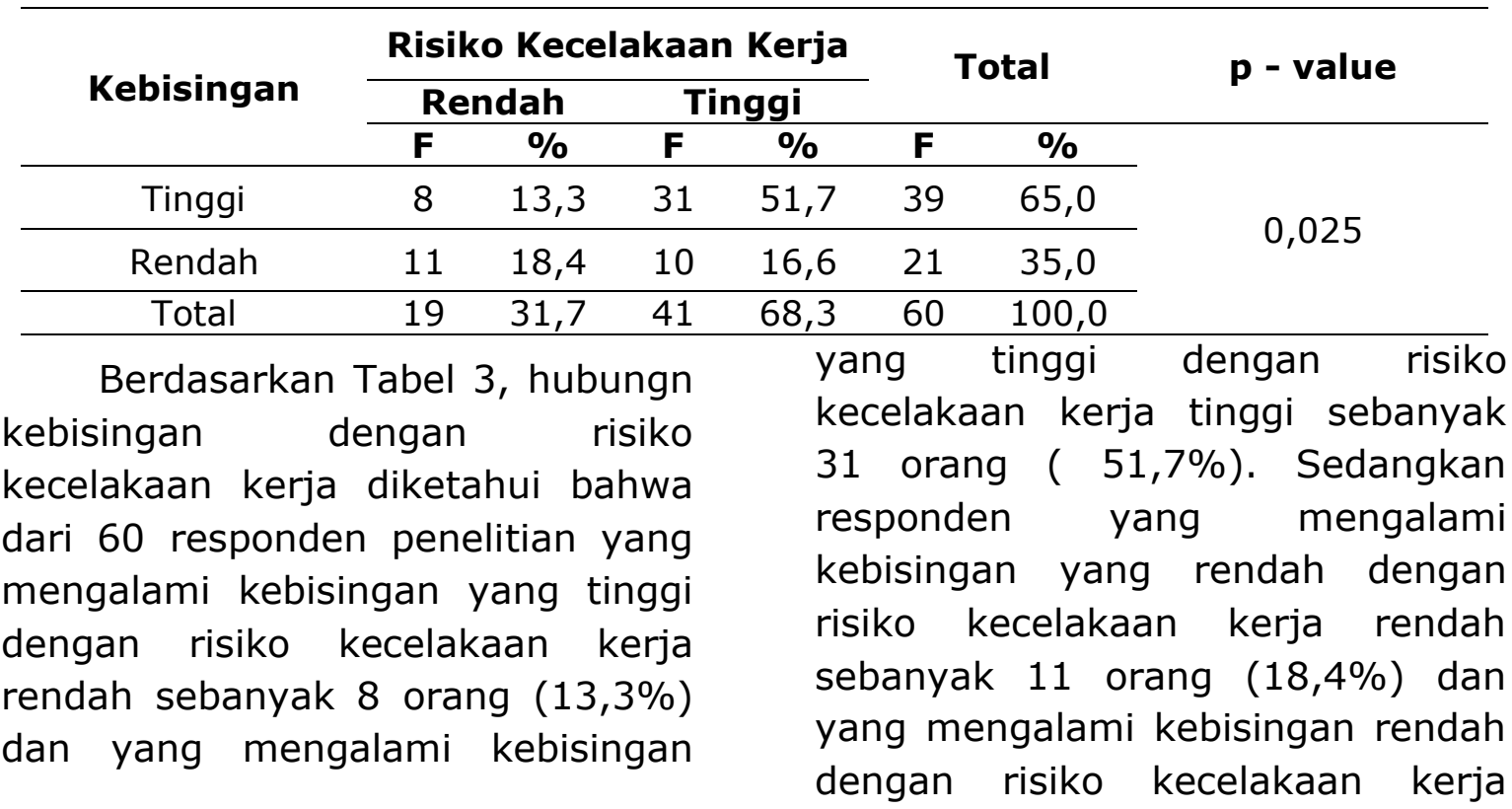


tinggi sebanyak 10 orang (16,6\%). Hasil uji statistik diperoleh nilai $p$ value adalah $0,025(p-<0,05)$ yang artinya ada hubungan kebisingan dengan risiko kecelakaan kerja.

Tabel 4. Hubungan Kelelahan dengan Risiko Kecelakaan Kerja

\begin{tabular}{|c|c|c|c|c|}
\hline \multirow{2}{*}{$\begin{array}{l}\text { Kelela } \\
\text { han }\end{array}$} & \multicolumn{2}{|c|}{$\begin{array}{c}\text { Risiko } \\
\text { Kecelakaan Kerja }\end{array}$} & \multirow{2}{*}{$\begin{array}{c}\text { Tot } \\
\text { al } \\
\text { F }\end{array}$} & \multirow{2}{*}{$\begin{array}{l}P \text { - } \\
\text { val } \\
\text { ue }\end{array}$} \\
\hline & $\begin{array}{c}\text { Rendah } \\
\text { F }\end{array}$ & $\begin{array}{l}\text { Tinggi } \\
\mathbf{F}\end{array}$ & & \\
\hline Berat & 9 & 35 & 44 & \\
\hline Ringan & 10 & 6 & 16 & $\begin{array}{r}0,0 \\
05\end{array}$ \\
\hline Total & 19 & 41 & 60 & \\
\hline
\end{tabular}

hubungan kelelahan dengan risiko kecelakaan kerja diketahui bahwa dari 60 responden penelitian yang mengalami kelelahan berat dengan risiko kecelakaan kerja rendah sebanyak 9 orang $(15,0 \%)$ dan yang mengalami kelelahan berat dengan risiko kecelakaan kerja tinggi sebanyak 35 orang (58,3\%). Sedangkan responden yang mengalami kelelahan ringan dengan risiko kecelakaan kerja rendah sebanyak 10 orang $(16,7 \%)$ dan yang mengalami kelelahan ringan dengan risiko kecelakaan kerja tinggi sebanyak 6 orang $(10,0 \%)$.

\section{B. Analisis Multivariat}

Untuk menganalisis pengaruh variabel independen terhadap variabel dependen tersebut dilakukan analisis regresi logistik dengan nilai $a$ (alpha) $=0,05$. Kriteria seleksi yang dilakukan dalam analisis ditetapkan dengan nilai $p<0,25$ dari hasil analisis menggunakan Metode Enter. Berdasarkan hasil analisis, kandidat variabel yang dimasukkan kedalam analisis dapat dilihat pada Tabel 5 :

Tabel 5. Seleksi Variabel Multivariat

\begin{tabular}{llc} 
No & Variabel & p-value \\
\hline 1. & Paparan Debu & 0,017 \\
\hline 2. & Kebisingan & 0,025 \\
\hline 3. & Kelelahan & 0,005 \\
\hline
\end{tabular}

Selanjutnya seluruh variabel tersebut yang melalui Metode Enter dan menjadi kandidat dimasukkan secara bersama-sama kedalam analisis regresi logistik. Hasil analisis regresi logistik dapat dilihat pada Tabel 6 :

Tabel 6. Hasil Regresi Logistik Tahap I

\begin{tabular}{|c|c|c|c|}
\hline No & Variabel & B & $\begin{array}{c}p- \\
\text { value }\end{array}$ \\
\hline 1. & Constant & $\begin{array}{c}- \\
2,244\end{array}$ & 0,009 \\
\hline 2. & $\begin{array}{l}\text { Paparan } \\
\text { Debu }\end{array}$ & 1,808 & 0,017 \\
\hline 3. & Kebisingan & 1,111 & 0,025 \\
\hline 4. & Kelelahan & 2,148 & 0,005 \\
\hline
\end{tabular}

Variabel yang valid dalam model multivariat adalah variabel yang mempunyai $p$-value $<0,05$. Berdasarkan hasil regresi logistik diatas, variabel kebisingan diperoleh hasil $p$-value $=0,101$ dimana nilai $p$-value $>0,05$ sehingga variabel tersebut dikeluarkan dari model. Kemudian dilakukan pengujian terakhir terhadap variabel paparan debu dengan nilai $p$-value $=0,014$ dan variabel kelelahan dengan nilai $p$ value $=0,005$, dikarenakan nilai $p$ value $<0,05$. Hasil analisis regresi logistik dapat dilihat pada Tabel 7 : 
Tabel 7. Seleksi Variabel Multivariat Tahap II

\begin{tabular}{llcc}
\hline No & Variabel & $\boldsymbol{p}$-value & OR \\
\hline 1. & $\begin{array}{l}\text { Paparan } \\
\text { Debu }\end{array}$ & 0,014 & 6,958 \\
\hline 2. & Kelelahan & 0,005 & 9,643 \\
\hline
\end{tabular}

Berdasarkan hasil uji regresi logistik tahap terakhir diketahui bahwa variabel yang paling berhubungan dengan risiko kecelakaan kerja dalam penelitian ini yaitu variabel kelelahan dengan nilai $p$-value $=0,003$ dan Odds Ratio $(\mathrm{OR})=9,643$ dengan CI 95\% $(2,180$ - 42,662). Hasil dapat dilihat di Tabel 8 :

Tabel 8. Hasil Regresi Logistik Tahap Terakhir

\begin{tabular}{llccc}
\hline No & Variabel & B & $\begin{array}{c}\boldsymbol{p} \text { - } \\
\text { value }\end{array}$ & OR \\
\hline 1. & Constant & $\begin{array}{c}- \\
1,738\end{array}$ & 0,023 & - \\
\hline 2. & $\begin{array}{l}\text { Paparan } \\
\text { Debu }\end{array}$ & 1,940 & 0,007 & 6,958 \\
\hline 3. & Kelelahan & 2,266 & 0,003 & 9,643 \\
\hline
\end{tabular}

Maka pemodelan regresi logistik analisis multivariat dengan persamaan sebagai berikut :

$$
\begin{gathered}
Y=a+\beta 1 X 1+\beta 2 X 2 \\
Y=-0,570+1,940(1)+2,268
\end{gathered}
$$

$$
\mathrm{Y}=3,638
$$

Dengan demikian nilai peluang atau probabilitas yaitu :

$$
\begin{gathered}
p=\frac{1}{(1+\exp (-y))} \\
p=\frac{1}{(1+\exp (-3,638))} \\
p=\frac{1}{(1+(0,026304))} \\
p=\frac{1}{(1,026304)} \\
p=0,9743
\end{gathered}
$$

Dengan demikian, probabilitas pekerja untuk mengalami kecelakaan kerja yang dipengaruhi oleh faktor paparan debu dan kelelahan yaitu sebesar 0,9743 atau $91,40 \%$.

\section{Kesimpulan}

Berdasarkan hasil penelitian dapat disimpulkan bahwa:

1. Ada hubungan paparan debu dengan risiko kecelakaan kerja pada pekerja di PT. Hutama Karya Infrastruktur.

2. Ada hubungan kebisingan dengan risiko kecelakaan kerja pada pekerja di PT. Hutama Karya Infrastruktur.

3. Ada hubungan kelelahan dengan risiko kecelakaan kerja pada pekerja di PT. Hutama Karya Infrastruktur.

4. Variabel yang berpengaruh terhadap risiko kecelakaan kerja yaitu paparan debu dan kelelahan, dan variabel yang paling dominan berpengaruh terhadap risiko kecelakaan kerja adalah Kelelahan.

\section{Daftar Pustaka}

Aronson, P.I. \& Ward, J.P.T., 2010. At a Glance Sistem Kardiovaskular. Jakarta: Erlangga.

Anizar. 2009. Teknik Keselamatan Dan Kesehatan Kerja di Industry. Graha Ilmu. Yogyakarta.

Benny L. Priatna dan Adhi Ari Utomo dalam Edhie Sarwono., 
dkk. 2002. Green Company Pedoman Pengelolaan Lingkungan, Keselamatan dan Kesehatan Kerja (LK3). PT. Astra International Tbk. Jakarta.

Darusin, Aria Gusti. 2012. Manajemen resiko dan Keselamatan dan Kesehatan Kerja. Faculty of Public Health. Universitas Andalas. Diakses dari Website: https://ariagusti.wordpress.co $\mathrm{m} / 2011 / 01 / 07 / m a n a j e m e n-$ risiko-dalam-keselamatandan-kesehatan-kerja/.

Julius, S. 2008. CLINICAL IMPLICATIONS OF PATHOPHYSIOLOGIC

CHANGES IN THE MIDLIFE HYPERTENSIVE PATIENTS. American Heart Journal, 122: 886-891.

Kurniawan, Yohanes., dkk. 2018. HUBUNGAN PENGETAHUAN, KELELAHAN, BEBAN KERJA FISIK, POSTUR TUBUH SAAT BEKERJA, DAN SIKAP PENGGUNAAN APD DENGAN KEJADIAN KECELAKAAN KERJA. Jurnal Kesehatan Masyarakat Volume 6, Nomor 4, Agustus 2018 (ISSN : 23563346).

Ningsih, Sari Narulita P. 2018. FAKTOR YANG BERHUBUNGAN DENGAN KELELAHAN PADA PEKERJA DIPO LOKOMOTIF PT. KERETA API INDONESIA
(PERSERO). Journal of Industril Hygiene and Occupational Health, Vol. 3 No. 1, Oktober 2018.

Nurmianto, Eko. 2003. Ergonomi Konsep Dasar dan Aplikasi. Prima Printing. Surabaya.

OHSAS 18001. Occupational Health and Safety Management System - Requirements.

Peraturan Pemerintah Republik Indonesia Nomor 50 tahun 2012. 2012. Sistem Manajemen Keselamatan dan Kesehatan Kerja (SMK3).

Santoso, Gempur. 2004. Manajemen Keselamatan dan Kesehatan Kerja. Ghalia Indonesia. Bogor Selatan.

Sulhinayatillah. 2017. FAKTOR FAKTOR YANG BERHUBUNGAN DENGAN KEJADIAN KECELAKAAN KERJA PADA KARYAWAN BAGIAN PRODUKSI DI PT. PP LONDON SUMATRA INDONESIA TBK, PALANGISANG CRUMB RUBBER FACTORY, BULUKUMBA SULAWESI SELATAN 2017. Fakultas Kedokteran Dan Ilmu Kesehatan. Universitas Islam Negeri Alauddin Makassar.

Undang-Undang Republik Indonesia Nomor 13 Tahun 2003 tentang Ketenagakerjaan. 
Wibowo, Fitra Agus. 2018. KAJIAN FAKTOR KEBISINGAN DAN DEBU TERHADAP PEKERJA DI PT. SURYA TOTO INDONESIA SERPONG, TANGERANG. Seminar Nasional Cendekiawan ke 4 Tahun 2018, ISSN (E) : 2540 - 7589. Universitas Trisakti.

Yunartha, Matda. 2016. HUBUNGAN PENGALAMAN KERJA DAN KELELAHAN DENGAN KECELAKAAN KERJA DI BAGIANNNN OPERASIONAL PT. ENERGI MEGA PERSADA (EMP) GELAM MUARO JAMBI TAHUN 2016. Scientia Journal Vol. 5 No. 02 Desember 2016 